\title{
Adsorption Performance of Human-like Collagen by Alkali-modified Kapok Fiber: A Kinetic, Equilibrium, and Mechanistic Investigation
}

\section{Liyao Cao}

Donghua University - Songjiang Campus: Donghua University

Hongchang Wang

Donghua University - Songjiang Campus: Donghua University

Hua Shen

Donghua University - Songjiang Campus: Donghua University

ruiliu Wang

donghua univercity

Fumei Wang

Donghua University - Songjiang Campus: Donghua University

Guangbiao Xu ( $\nabla$ guangbiao_xu@dhu.edu.cn )

Donghua University College of Textiles

\section{Research Article}

Keywords: Alkali-modified Kapok, human-like collagen, adsorption kinetics, diffusion

Posted Date: December 8th, 2021

DOI: https://doi.org/10.21203/rs.3.rs-1013583/v1

License: (1) This work is licensed under a Creative Commons Attribution 4.0 International License.

Read Full License

Version of Record: A version of this preprint was published at Cellulose on March 10th, 2022. See the published version at https://doi.org/10.1007/s10570-022-04489-7. 


\section{Adsorption performance of human-like collagen by alkali-modified Kapok}

fiber: a kinetic, equilibrium, and mechanistic investigation
Liyao Cao a, Hongchang Wang ${ }^{\mathrm{a}}$, Hua Shen ${ }^{\mathrm{a}, \mathrm{b}}$, Ruiliu Wang ${ }^{\mathrm{a}}$, Fumei Wang ${ }^{\mathrm{a}, \mathrm{b}}$, Guangbiao $\mathrm{Xu}^{\mathrm{a}, \mathrm{b}, *}$
${ }^{\mathrm{a}}$ College of Textiles, Donghua University, Shanghai 201620, China
${ }^{\mathrm{b}}$ Key Laboratory of Textile Science and Technology Ministry of Education, Donghua University, Shanghai 201620, China

Abstract: Collagen-based dressings achieve excellent repair of the skin during metical cosmetology, which has received a lot of attention recently. Although great progress has been made on using biomass fiber as dressing carrier, more research is required on developing novel biomass fibers because of the limitations of (i.e., high cost and complex processing) of existing materials. In this study, the adsorption behaviors of two human-like collagen were studied by examining the Kapok fiber that was modified using alkali consisting of various amounts of the mass fraction. Results show that the alkali-modified Kapok fiber surface becomes rough with vertically arranged grooves, and the cross-section depicts the hollow cavity structure. The composition analysis of alkali modified Kapok shows that alkali dissolves part of the hemicellulose and lignin. Additionally, the surface energy rises sharply and the water contact angle changed from hydrophobic to hydrophilic. The adsorption amount of raw Kapok fiber is around $0.6 \mathrm{~g} / \mathrm{g}$, which accounts for only one twenty-first of the adsorption amount of alkali-treated Kapok (around 12.6g/g), while the equilibrium adsorption amount was not sensitive to alkali concentration. The kinetics of human-like collagen followed both Quasi first and Quasi second order kinetic model, implying that the adsorption process where characterized by both physisorption and chemisorption. Finally, characterization of the AKF-2 coupled with the studies based on the inter-particle diffusion model showed a three-step of human-like collagen diffusion consisting of surface diffusion, inter-fiber diffusion and fiber' hollow cavity diffusion. Our results demonstrate a perfect high absorption performance of Kapok fiber providing a potential for application of collagen-base dressings.

Keyword: Alkali-modified Kapok; human-like collagen; adsorption kinetics; diffusion;

\section{Introduction} commercialize industries. Medical cosmetology primarily focuses on repairing and reshaping various parts of the human body through drugs, surgery, medical equipment and other traumatic or irreversible 
medical technology methods. However, the application of metical cosmetology can inevitably damage the barrier function of the skin and cause postoperative complications, including skin pigmentation, contact dermatitis, superficial ulcers and other skin diseases. Among several methods to deal with skin damage, postoperative repair dressing is one of the most widely and commonly used methods. Recently, collagen is the main dressings used in postoperative repair dressings to deal with skin damage. The research of collagen-based dressings are mainly focused on three areas: 1) preparation (Ge et al., 2018); 2) healing mechanism (Ge et al., 2018; Lozeau et al., 2018; Pallaske et al., 2018); and 3) application (Ye et al., 2014). When collagen is used, a biomass fiber based dressingcarrier is widely used including seaweed (Andryukov et al., 2020), chitin (Hao et al., 2020) and protein (Guo et al., 2020) fibers. Although great progress has been made on using biomass fiber as dressing carried, more research is required on developing novel biomass fibers because of the limitations of existing materials (high cost and complexity of process). Additionally, novel biomass fiber can help to maintain product diversity and provide avenues of opportunities to examine the effects of different biomass fiber dressings on skin problem.

Kapok is a biomass fiber known for its lightweight(Yang et al., 2018) and thinness(20 45 $\mu \mathrm{m})$ among all the natural fibers. Single Kapok fiber has a big cylindrical hollow cavity structure and is characterized nearly transparent and very thin cell wall (Abdullah et al., 2010). Moreover, it has a hollow rate of $>86 \%$, which is the highest hollow rate in nature fiber (Xiang et al., 2013). It has excellent moisture absorption and breathability characteristics due to the physicochemical property mentioned above (Yang et al., 2018). Furthermore, Kapok fiber has superior biocompatibility, biodegradability and natural antibacterial properties, with an antibacterial rate of $>91.9 \%$ (Wang et al., 2015). These unique properties have promoted Kapok fiber as dressing carrier materials for the collagen-based postoperative repair dressing. Because of the hydrophobic characteristics of Kapok fiber, earlier studies were mainly focused on oil removal (Dong et al., 2015b, c; Zhang et al., 2021), wastewater treatment (Sun et al., 2018; Wang and Wang, 2018; Wang and Zheng, 2017) as well as dye adsorption ( $\mathrm{Li}$ et al., 2015; Zhang et al., 2015). Nevertheless, there have been no more studies to evaluate the performance of Kapok as a potential fiber for collagen-based dressings.

In collagen-based dressings, adsorption characteristics play an important role in the overall performance of the postoperative repair. In the study, the adsorption performance of alkali modified 
Kapok fiber for various human-like collagen was quantified by evaluating the equilibrium time and amount of adsorption. Meanwhile, the effect of different alkali concentrations on the adsorption performance were also examined during this study. Additionally, the adsorption kinetic model of human-like collagen on the Kapok fiber, including two Quasi (first- and second-order kinetic models) and a Weber-Morris model were discussed. Finally, the adsorption process and mechanism were investigated. The alkali-modified Kapok fiber has potential to be used as an alternative material in collagen-based dressings application.

\section{Material and methods}

\section{Alkali-modified Kapok fiber}

The Kapok fiber used in this experiment came from Pate County, Java Tengah, Indonesia. The samples $(6 \mathrm{~g})$ were put into a beaker with different $\mathrm{NaOH}$ solution mass fractions $(2 \%, 4 \%, 6 \%, 8 \%)$, which was then placed in a thermostat water bath (HH-4, ZENROE, China) to maintain a constant temperature around $70^{\circ} \mathrm{C}$ for alkali-modification. After 6 hours of reaction/treatment, the Kapok fibers were washed with deionized water and dried naturally at room temperature $\left(26^{\circ} \mathrm{C}, 68 \%\right)$ to obtain alkali-modified samples. The obtained samples were marked as AKF-2, AKF-4, AKF-6 and AKF-8, which refers to $2 \%, 4 \%, 6 \%$ and $8 \%$ alkali concentration, respectively.

\section{Characterization of Fibers}

Their surface and cross-sectional morphologies were examined using field emission scanning electron microscopy (SU8010, Hitachi, Japan) by exerting an accelerating voltage of $20 \mathrm{kV}$ on a simple sputter-coated with gold. Fourier transformed infrared (FTIR) spectrometer (Nicolet6700, Thermo Fisher, USA) was used to record diversification between raw and alkali-modified fibers. Xray diffraction $(\mathrm{XRD})$ experiments were executed on a diffractometer (D/MAX-2500 PC, Rigaku, Japan) by applying $\mathrm{Cu} \mathrm{Ka}$ radiation $(\lambda=0.154 \mathrm{~nm}, 40 \mathrm{kV}, 200 \mathrm{~mA})$ to separate the crystal phase of the raw and alkali-modified fibers. Shredded fibers were scanned at a step size of $0.05^{\circ}$ with $2 \theta$ between $5^{\circ}$ and $60^{\circ}$. Cellulose samples are routinely analyzed by X-ray diffraction to determine the crystallinity (French, 2014; French and Santiago Cintrón, 2013). The Peak deconvolution was 
performed by curve fitting to the observed pattern (French, 2020). In particular, subtracting instrumental background before peak deconvolution ensures a stable baseline fitting and reduces fitting error (Yao et al., 2020). The crystallinity $(x)$ was calculated using the following equation:

$$
x=\frac{\sum I_{c}}{\sum I_{c}+\sum I_{a}} \times 100 \%
$$

Where $\sum I c$ represents the peak diffraction integral intensity crystalline region of the samples, and $\sum I a$ represents the intensity scattered by the amorphous fraction of the material.

The surface energies of samples, including surface tension, and polar and dispersion-component were calculated based on Owens-Wendt-Rabel-Kaelble method (OWRK). The slope and intercept of fitting line with three different liquids (water, ethylene glycol, ethanol) were obtained using the OWRK method (Table 1). The OWRK method expresses the surface energy between liquid and solid using the following equations:

$$
\delta_{l}(1+\cos \theta)=2\left(\sqrt{\delta_{s}^{d} \delta_{l}^{d}}+\sqrt{\delta_{s}^{p} \delta_{l}^{p}}\right)
$$

$$
\frac{(1+\cos \theta)}{2} \cdot \frac{\delta_{1}}{\sqrt{\delta_{l}^{d}}}=\sqrt{\delta_{s}^{p}} \cdot \sqrt{\frac{\delta_{l}^{p}}{\delta_{l}^{d}}}+
$$

$$
\sqrt{\delta_{s}^{d}}
$$

where $\delta_{l}$ is surface energy of liquid, $\delta_{s}$ is surface energy of solid, $\cos \theta$ is the contact angle, while superscript $\mathrm{p}$ and $\mathrm{d}$ represent polar and dispersion components, respectively. (Kaelble, 1970; Murray et al., 2012; Owens and Wendt, 1969; Rabel, 1971). Eq. (3) can be further expressed into slope and intercept as follows:

$$
\begin{aligned}
& \mathrm{y}=\sqrt{\delta_{s}^{p}} \cdot x+\sqrt{\delta_{s}^{d}} \\
& \mathrm{x}=\sqrt{\frac{\delta_{l}^{p}}{\delta_{l}^{d}}}
\end{aligned}
$$

Table 1 Properties of liquids for surface energy measurement of fibers.

\begin{tabular}{cccc}
\hline Liquid type & Surface tension $(\mathrm{mN} / \mathrm{m})$ & $\begin{array}{c}\text { Polar component }{ }^{\mathrm{a}} \\
(\mathrm{mN} / \mathrm{m})\end{array}$ & $\begin{array}{c}\text { Dispersion component } \\
(\mathrm{mN} / \mathrm{m})\end{array}$ \\
\hline Water & 72.1 & 52.2 & 19.9 \\
Ethylene glycol & 48.0 & 29.0 & 19.0 \\
Ethanol & 22.1 & 4.6 & 17.5 \\
\hline
\end{tabular}




\section{Chemical composition}

Composition analysis of samples were performed according to standardized methods of fibrous materials. The proportions of the chemical composition were based on GB/T standard methods. Holocellulose (sum of the cellulose and hemicelluloses), acid-soluble lignin and Klason-lignin were determined according to GB/T 2677.10-1995, GB/T 2677.8-94 and GB/T 10337-2008, respectively. The cellulose of samples was quantified using TAPPI standard methods, followed by averaging of the results and comparison among experiments.

\section{Characterization of Human-like collagen}

Two types of human-like collagen, Trauer (Guangzhou Trauer Biotechnology Co., Ltd.) and MeiQ (Yangzhou Merry Bio-Technology Co., Ltd.), was employed in this experiment, with the pure water as blank simple. The densities and surface tensions of three liquids were measured by a tension meter (DCAT11, Dataphysics, Germany), while viscosities were determined using a viscosimeter (DV2TLV, Brookfield, USA) at a temperature of $25^{\circ} \mathrm{C}$, with a spindle speed of $200 \mathrm{rpm}$ and a rotor (SC4-18(18)). The $\mathrm{pH}$ of liquids was determined by $\mathrm{pH}-220 \mathrm{~B}$ from China. The detailed properties of experimental liquids are shown in Table 2.

Table 2 Properties of liquids for experiment

\begin{tabular}{ccccc}
\hline Solution type & Density $\left(\mathrm{g} / \mathrm{cm}^{3}\right)$ & Viscosity $(\mathrm{mPa} \mathrm{s})$ & Surface tension $(\mathrm{mN} / \mathrm{m})$ & $\mathrm{pH}$ \\
\hline Trauer & 1.00 & 1.65 & 48.14 & 5.42 \\
MeiQ & 1.01 & 20.98 & 37.90 & 5.33 \\
Water & 1.01 & 1.07 & 68.38 & 7.18 \\
\hline
\end{tabular}

\section{Adsorbed morphology}

The adsorption process on the fiber surface was observed and recorded using a microscope consisting of an optical contact angle meter OCA15EC. First, the fiber was placed on the sample holder, and the horizontal screw rod was regulated to ensure that the fiber was in a horizontal state. Second, 1 to 10-micron droplets were sprayed using the humidifier, which was directed onto the fiber 
from a tube ( $3 \mathrm{~cm}$ in diameter) to form droplets followed by the condensation of small droplets into larger droplets. Finally, the adsorbed morphology was observed and recorded with the optical microscope and CCD components.

The fiber hollow cavity was used for droplet penetration by taking a few samples on a glass slide and dropping the droplets using a disposable pipette. The penetration of droplets into the fiber hollow cavity was captured by a polarizing microscope (ECLIPSE LV 100 POL, Nikon, Japan).

\section{Evaluation of liquid sorption rate}

As shown in Fig. 1, the adsorption experiment was carried out using the tensiometer DCAT11. First, the sample was evenly distributed into a cylindrical container (2) that consisted of a length of $40 \mathrm{~mm}$ and an inner diameter of $12 \mathrm{~mm}$. The sample filling mass, length and density were $0.2 \mathrm{~g}, 20$ $\mathrm{mm}$ and $0.084 \mathrm{~g} / \mathrm{cm}^{3}$, respectively. Then, the sample container (2) was hung under the microbalance using a unique sample rack. The beaker containing the test liquid was placed in the constant temperature liquid reservoir (3) on the elevator (5). The temperature of the test liquid was set to $25^{\circ} \mathrm{C}$ through a thermostatic bath. Finally, recording was done by opening computer (6) and testing the software performance. The change in absorbed mass was recorded using the microbalance (1) at the same intervals and plotted in the form of a curve using the computer (6).

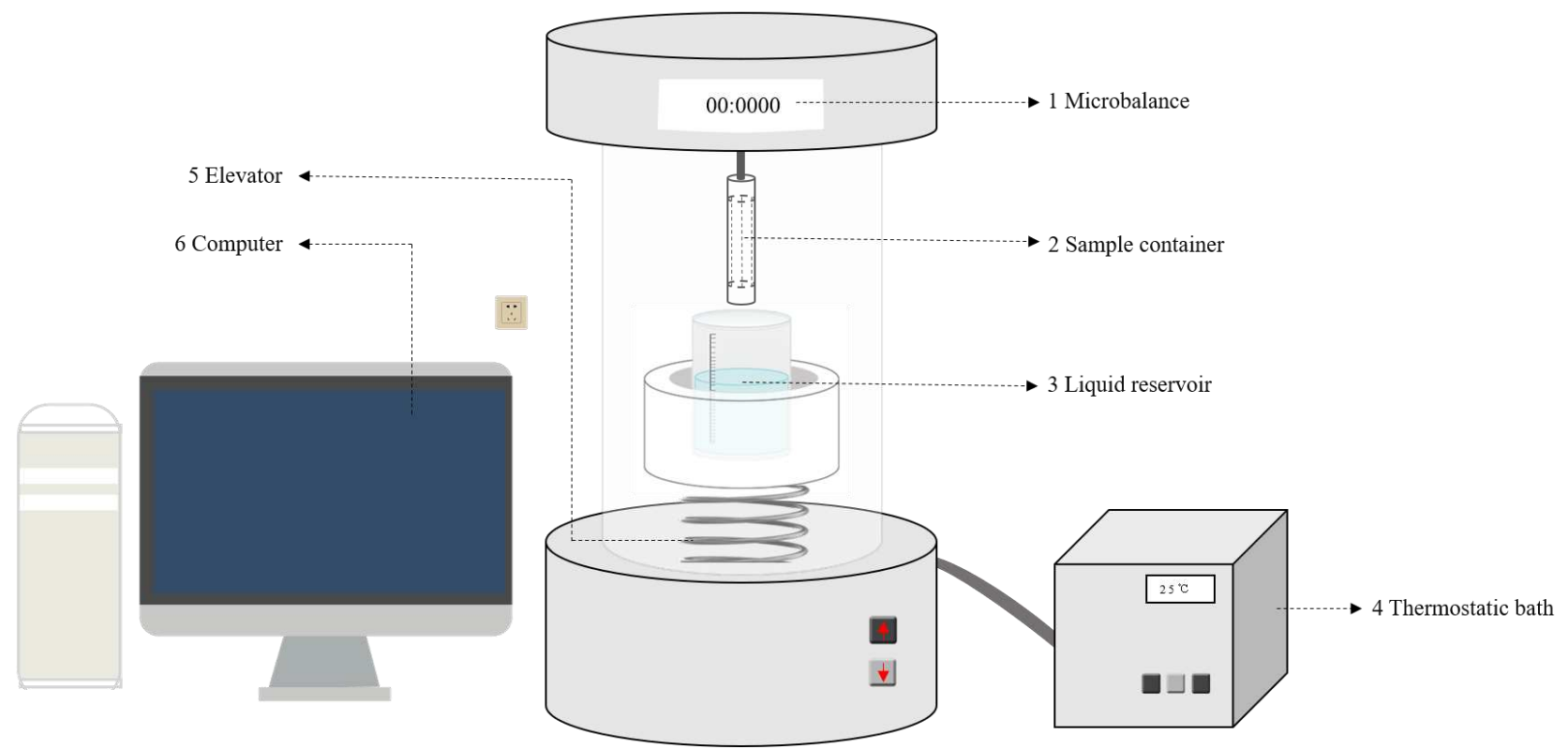

Fig. 1. Diagram of device for adsorption 


\section{Results and discussions}

\section{Characterization of fiber}

148

\section{Morphology and structure}

The morphologies of Kapok fibers (raw and different alkali modification) are illustrated in Fig.

2. Because of the plant wax coverage, the raw Kapok fiber shows a cylindrical shape with a smooth surface (Fig. 2(a)). Following alkali modification (Fig. 2(f-j)), the fiber surface becomes rough with vertically arranged grooves due to the shedding of surface plant wax. As the modified alkali concentration increases from $2 \%$ to $8 \%$, severe damage on the surface structure was observed on AKF-8(Fig. 2(j)), consisting of apparent traces of alkali corrosion.
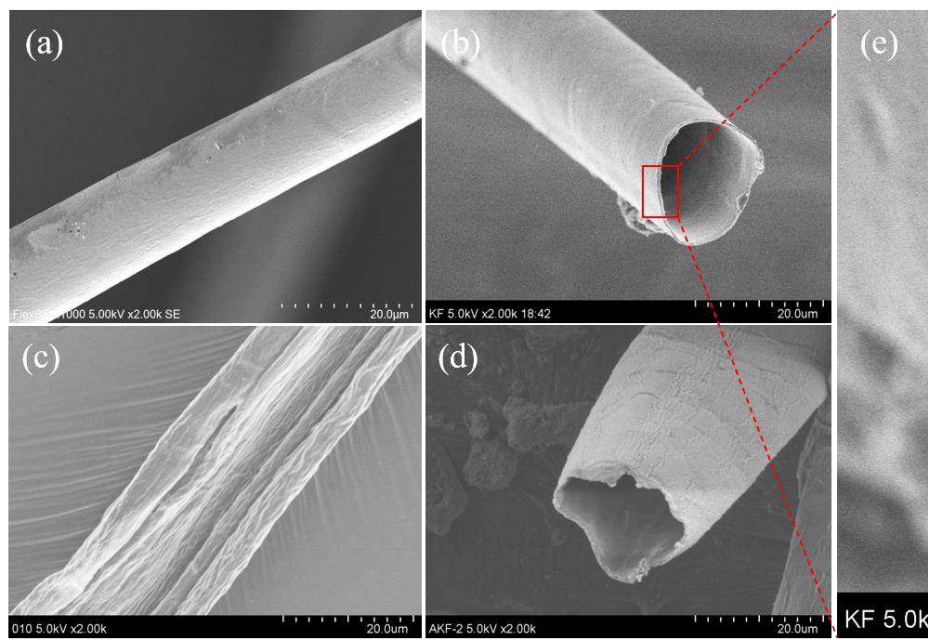

(d)
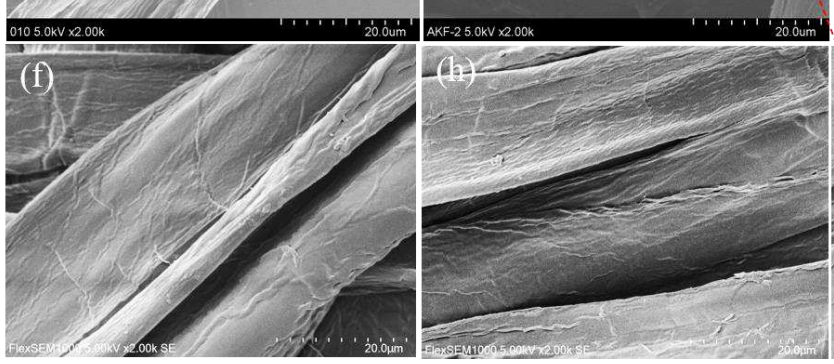

KF $5.0 \mathrm{kV} \times 15.0 \mathrm{k} 18.45$ 3.óoum

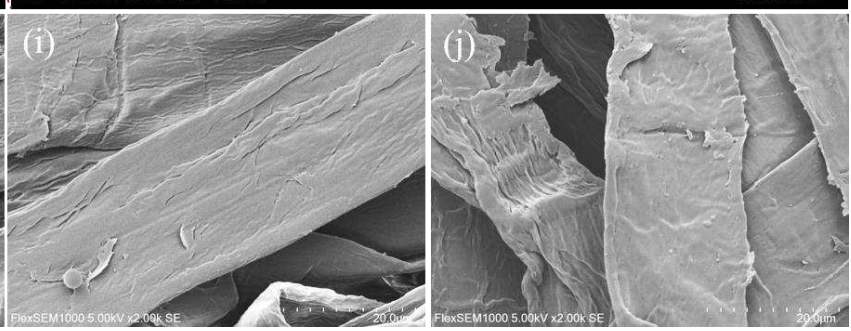

Fig. 2. SEM image of surface morphologies in Kapok fiber(a), AKF-2(c)(d), AKF-4(f), AKF-6(g) and AKF-8(h) and the cross-section in Kapok fiber(b) (g) and AKF-2(d).

Fig. 2(b) (d) shows the cross-sections of raw Kapok fiber and AKF-2. The raw Kapok fiber has a hollow cavity structure consisting of numerous multilevel buckling micropores in the cell wall Fig. 2(e). Several studies have found excellent oil absorption capacity in the Kapok fiber largely because oil can easily enter the hollow cavity through the open ends of the fiber wall and through the multi- 
level buckling micropores on cells (Dong et al., 2015a) (Dong et al., 2014). As shown in Fig. 2(d), the AKF-2 still depicts the hollow cavity structure with a thinner cell wall, indicating that the fibril structure is still intact. When adsorption occurs, the liquid can still enter the hollow cavity through the open ends of the fiber wall. Previous studies (Wang et al., 2012) have also shown that the appropriate $\mathrm{NaOH}$ modification is beneficial for improving absorbency depending on the modification concentration, temperature and time.

\section{Composition analysis}

The absorption peaks at $3400 \sim 3200 \mathrm{~cm}^{-1}$ and $2918 \sim 2901 \mathrm{~cm}^{-1}$ are attributed to $\mathrm{OH}$ and C-H's stretching vibration, respectively. These peaks are characteristics of the presence of cellulose (Andreeva et al., 2002). Fig.3(a) shows that the raw Kapok fiber has two absorption peaks at 3335.36 $\mathrm{cm}^{-1}$ and $2919.35 \mathrm{~cm}^{-1}$. However, no significant changes were observed as the alkali concentration increased, indicating no damage to the cellulose of the Kapok fiber. The absorption peaks at 1736.14 $\mathrm{cm}^{-1}, \quad 1593.44 \mathrm{~cm}^{-1}$ and $1239.33 \mathrm{~cm}^{-1}$ are attributed to the carbonyl group, the aromatic ring skeleton group, and the phenolic hydroxyl group; respectively, which are characteristics of absorption peak for lignin. It can be seen from Fig.3(a) that the absorption peaks start to disappear at $1736.14 \mathrm{~cm}^{-1}$ and $1239.33 \mathrm{~cm}^{-1}$, and the absorption peak became weaker at $1593.44 \mathrm{~cm}^{-1}$, indicating the partial removal of lignin. The absorption peaks about alkanes $\left(1371.00 \mathrm{~cm}^{-1}\right.$ and $\left.2919.35 \mathrm{~cm}^{-1}\right)$ become weaker after alkali modification.

Fig.S1 shows that the diffraction peaks of raw fiber and alkali-modified Kapok fiber have no significant fluctuations, around $15.8^{\circ}, 22.4^{\circ}$ and $34.6^{\circ} 2 \theta$. It indicates that the crystal structure of cellulose has not changed by alkali-modified, and the profile has been considered as the pure amorphous cellulose XRD profile (Yao et al., 2020). And the Fig.S2 shows the peak deconvolutions of raw fiber and alkali-modified Kapok fiber, the crystallinity using the ratio of the crystalline peak areas and the total XRD profile area were calculated by peak deconvolution method after subtracting the background intensity. Fig.3(b) shows that the raw fiber's crystallinity is $35.71 \%$, which is likely due to presence of amorphous components including lignin, hemicellulose, and wax. The crystallinity increased from $35.71 \%$ to $48.22 \%$ following the increase in alkali concentration from $2 \%$ to $6 \%$. Further increases in alkali concentration from $6 \%$ to $8 \%$ resulted in dropping fiber's crystallinity from 
$48.22 \%$ to $43.94 \%$. The increase in crystallinity after alkali treatment can be associated with the dissolution of free molecular chains in the amorphous region. The dissolution of free molecular chains increased the proportion of crystalline regions, thereby increasing the crystallinity.
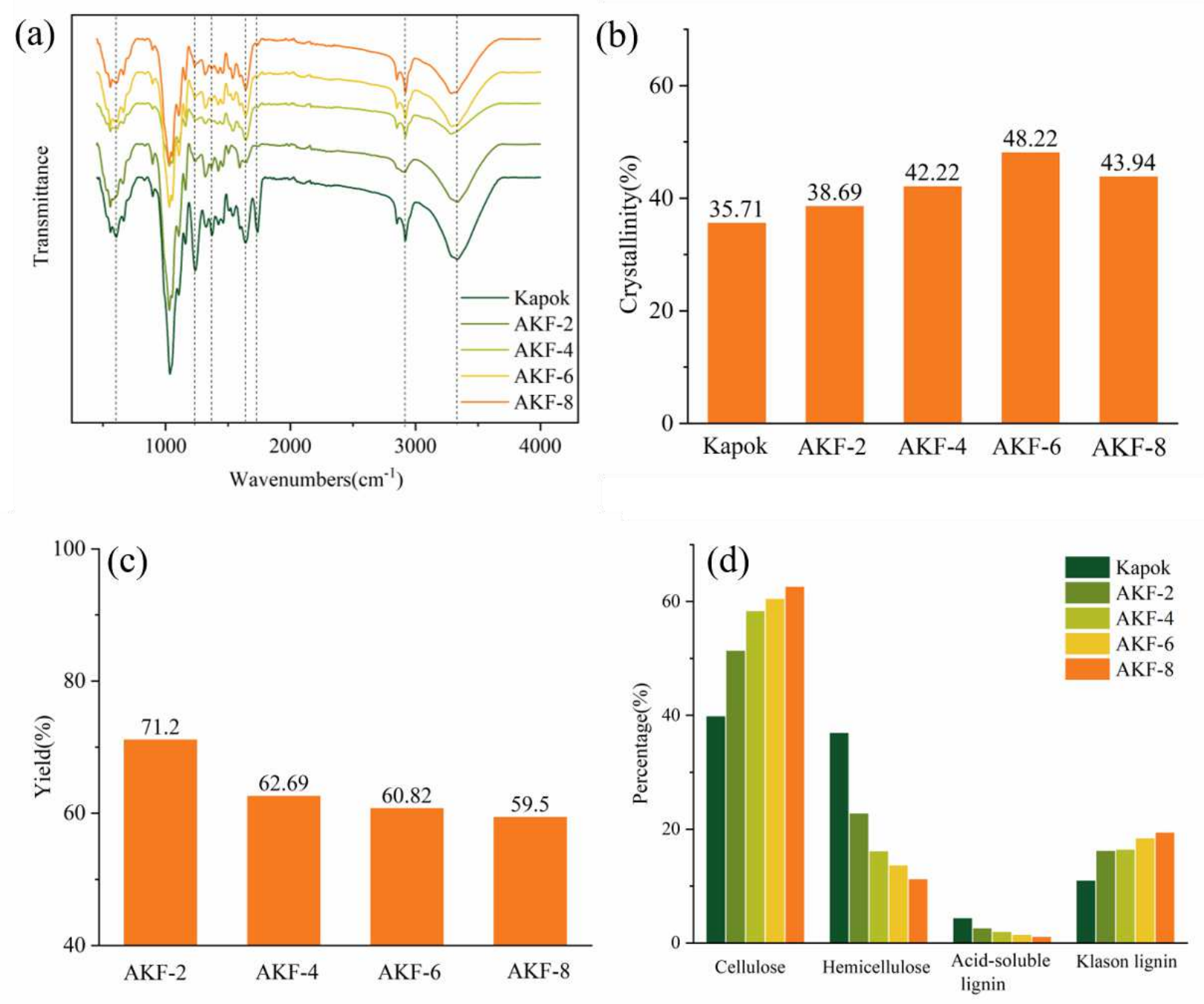

Fig. 3. FTIR spectra (a), Crystallinity (b) and Chemical Component(d) of Kapok, AKF-2, AKF-4, AKF-6 and AKF-8 and Yield(c) of AKF-2, AKF-4, AKF-6 and AKF-8.

The results obtained by examining the yield and chemical components of alkali-modified Kapok fiber are summarized in Fig. 3(c)(d). As shown in Fig. 3(c), the yield decreases from $71.2 \%$ to 59.5\% as the alkali concentration increases from $2 \%$ to $8 \%$. Likewise, the raw Kapok fiber mainly consists of cellulose (39.95\%), hemicellulose (37.01\%), acid-soluble lignin (11.09\%) and Klason lignin (4.46\%) (Fig. 3d). Results also show that the chemical composition of different alkali-modified Kapok fibers has a substantial effect on the hemicellulose and lignin content. For example, 38.17\% of hemicellulose and $39.46 \%$ of acid-soluble lignin were removed in AKF-2, while $69.46 \%$ of 

that the proportion of cellulose and Klason lignin experience an upward trend. The results indicate that the alkali dissolves part of the hemicellulose and lignin; however, the cellulose and Klason lignin are insensitive to the alkali concentration.
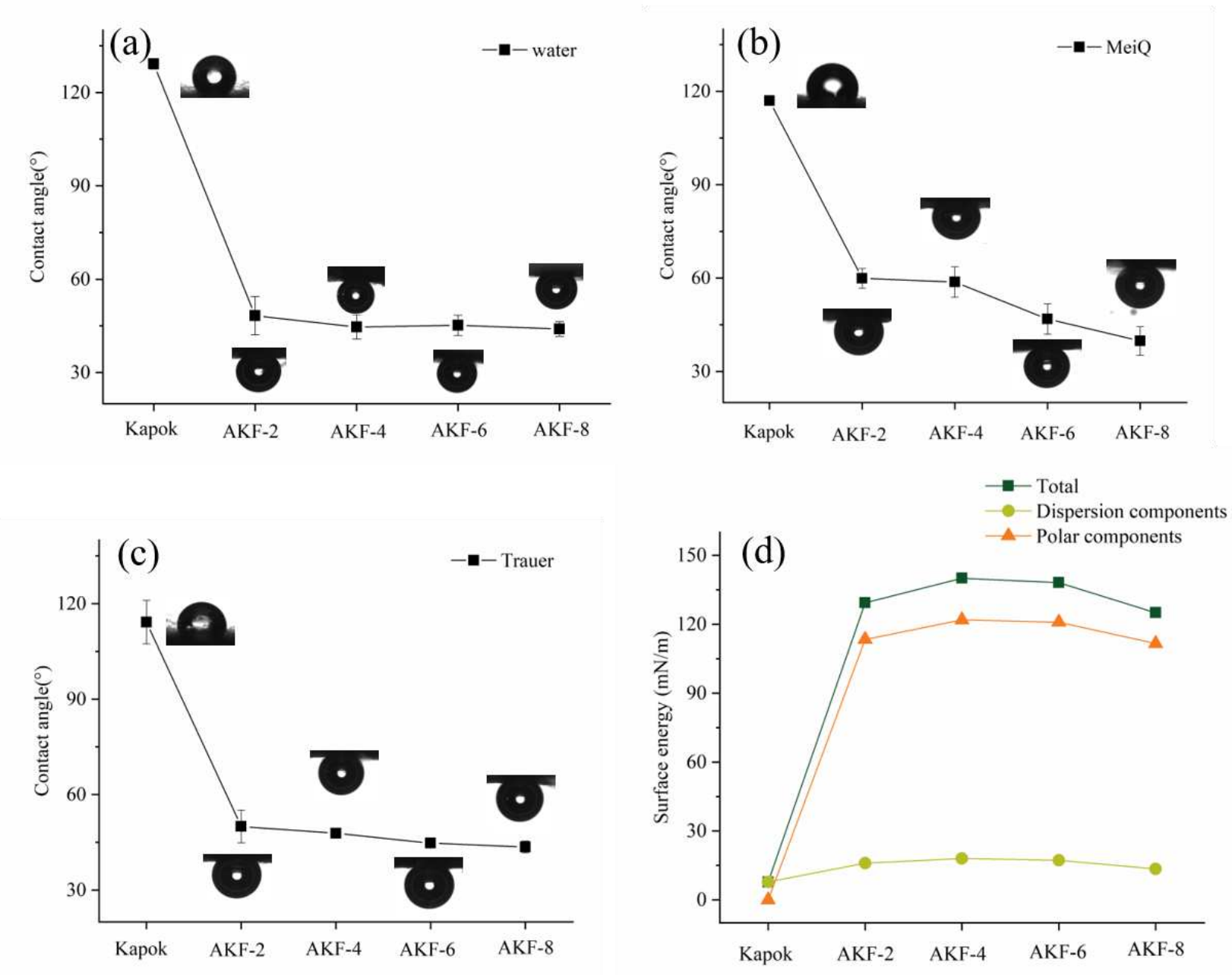

Fig. 4. Contact angle of Kapok, AKF-2, AKF-4, AKF-6 and AKF-8 on Water (a), MeiQ (b) and Trauer (c), respectively. Surface energy (d) of Kapok, AKF-2, AKF-4, AKF-6 and AKF-8.

To characterize the surface property of fibers, the contact angle of liquid was measured. As shown in Fig. 4(a), the raw Kapok fiber showed the water contact angle was $129.2^{\circ}$, which is considered as a hydrophobic surface. However, the water contact angle decreased below $50^{\circ}$ with decreasing concentration of alkali ( $\left.2 \mathrm{wt} \%: 48.3^{\circ}, 4 \mathrm{wt} \%: 44.6^{\circ}, 6 \mathrm{wt} \%: 45.2^{\circ}, 8 \mathrm{wt} \%: 44^{\circ}\right)$, the AKF- 
collagen showed a similar trend (Fig. 4(b)(c)). The lower contact angle achieved in alkali-modified fiber was supposed to be related with the surface energy. As depicted in Table S1, the surface energy of fiber rose rapidly from $7.80 \mathrm{mN} / \mathrm{m}$ to $125.05-140.06 \mathrm{mN} / \mathrm{m}$ with polar component playing a central role in stimulating the surface energy. On the other hand, Fig. 4 (d) shows that the surface energies increase with an increase in $\mathrm{NaOH}$ concentration from $2 \%$ to $4 \%$, with the highest surface energy of $140.06 \mathrm{mN} / \mathrm{m}$ at $4 \% \mathrm{NaOH}$ concentration. However, there was a downward trend in surface energies with an increase in $\mathrm{NaOH}$ concentration from $4 \%$ to $8 \%$. Generally, the higher surface energy of the substance indicates the better wettability of water on the surface and the smaller contact angle of water. Ko et al. (Ko et al., 1981) also suggested that the surface energy increases with the rise in hydrophilic compared to the hydrophobic groups. In this study, the $\mathrm{NaOH}$-modification removed the surface wax and exposed hydrophilic hydroxyl groups, which played an important role in hydrophilicity and fiber-matrix adhesion.

\section{Characterization of adsorption capacity}

Fig. 5(a)-(b) shows the equilibrium adsorption amount $\left(q_{e}\right)$ and equilibrium time $\left(t_{s}\right)$ of fibers. The absorption curves of water and human-like collagen to alkali-modified Kapok fibers are shown in Fig. 5(c)-(f). Results showed that the adsorption amount of raw Kapok fiber is around 0.6g/g, which accounts for only one twenty-first of the adsorption amount of alkali-treated Kapok. Given that the adsorption amount was almost negligible, we did not proceed with further analysis of the adsorption curve. The equilibrium time of AKF-2 to MeiQ was 1399.80 s, while that of Water and Trauer were only $274.80 \mathrm{~s}$ and $300.00 \mathrm{~s}$, indicating that Water and Trauer had an adsorption time that was shorter than MeiQ by approximately 4-5 times. The equilibrium adsorption amounts of water, MeiQ and Trauer were $12.61 \mathrm{~g} / \mathrm{g}, 11.96 \mathrm{~g} / \mathrm{g}$ and $12.10 \mathrm{~g} / \mathrm{g}$; respectively, without significant variation. Similar trends were found in the AKF-4, AKF-6 and AKF-8.

It is likely that the difference in equilibrium time is related to changes in liquid viscosity. As illustrated in Table 1, water and Trauer have similar liquid viscosity resulting in similar adsorption times. However, the viscosity of MeiQ's $(20.98 / \mathrm{mPa})$ was 20 times higher than water and Trauer. The fiber has small particle size and weak adhesion to low-viscosity liquids, but large particle size and strong adhesion to high-viscosity liquids (Dong et al., 2015a). MeiQ with high viscosity is more likely 
to be around the Kapok assembly's pores, which can prevent the liquid from entering the interior.
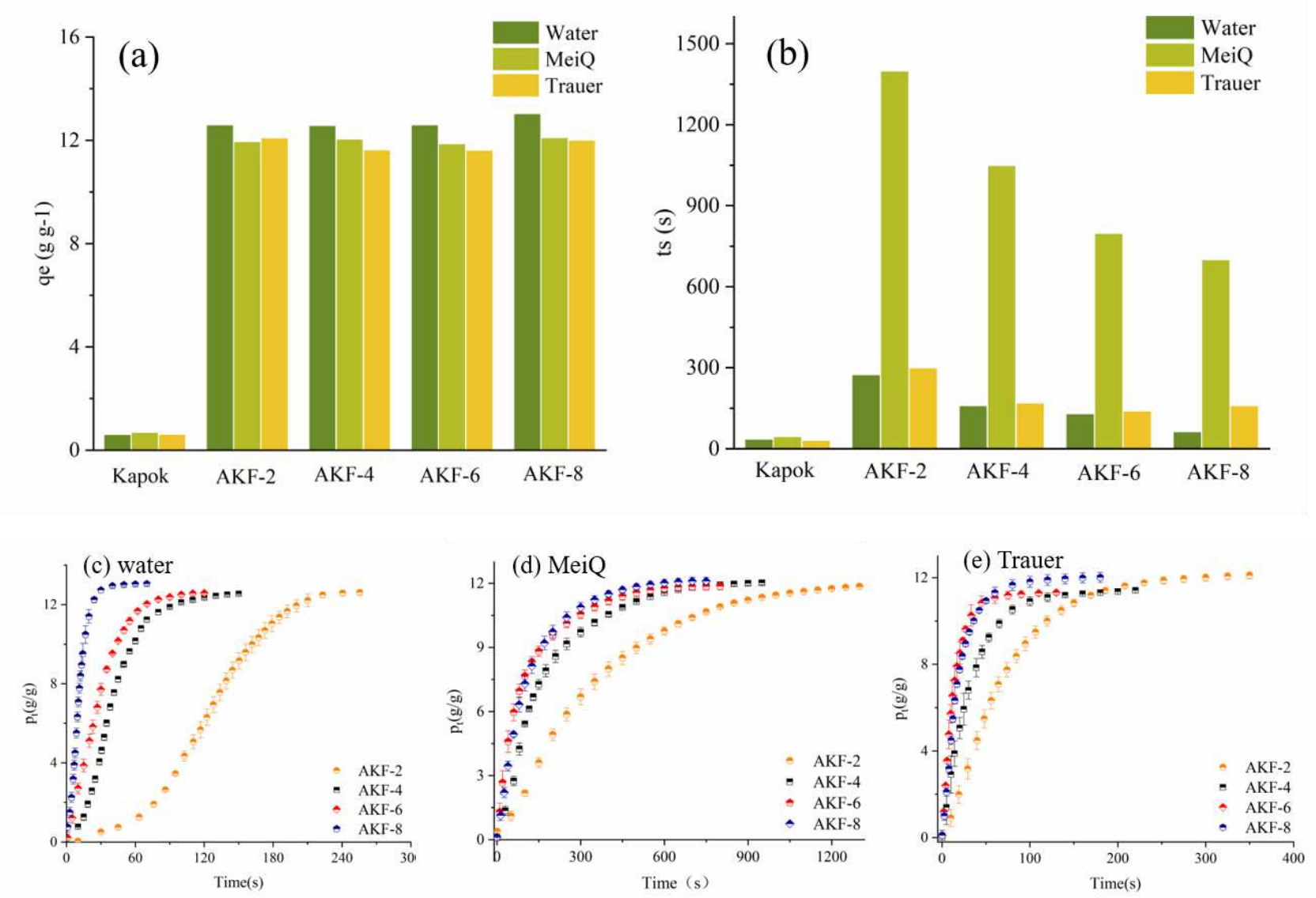

Fig. 5. Adsorption curves of AKF-2, AKF-4, AKF-6 and AKF-8 on Water (a), MeiQ (b) and Trauer (c), respectively, Symbols represent an average of three trials and error bars plotted as a standard deviation.

However, it is noteworthy that the equilibrium adsorption time had inverse relationship with the alkali concentration. The equilibrium time of AKF-4 for MeiQ was $169.80 \mathrm{~s}$, which was shorter than that of AKF-2 by $49.97 \%$. The adsorption time in AKF-6 showed similar trend as AKF-4, with AKF6 shorter than AKF-2 by $42.99 \%$. For AKF-8, there were more significant gaps in equilibrium adsorption time, but the gaps were shortened at $24.98 \%$ for the MeiQ. The adsorption time showed similar tendency for water and Trauer, which was likely due to an increase in the alkali concentration that exposed more hydrophilic groups due to the removal of fiber surface wax. Compare to the equilibrium time, the equilibrium adsorption amount of AKF-2 on three different liquids was similar under the same filler density $(0.0884 \mathrm{~g} / \mathrm{cm} 3)$, with only an $0.65 \mathrm{~g} / \mathrm{g}$ discrepancy between the smallest in MeiQ and the largest in water. A similar result appears in AKF-2, AKF-4, AKF-6 and AKF-8 to the adsorption of liquids. Besides, as illustrated in Table S2, different alkali-modification seems to exert negligible influence on the equilibrium adsorption amount for three liquids, with only $0.1 \mathrm{~g} / \mathrm{g}$ difference for AKF-2 and AKF-8. Several studies have reported that the oil absorbency of the Kapok 
assembly's depend on effective inter-fiber pore volumes and hollow cavity structure (Dong et al., 2015a) (Abdullah et al., 2010) (Rengasamy et al., 2011). Therefore, it is likely that the four fibers mentioned above have a minimal difference in equilibrium adsorption amount largely due to same filler density $(0.0884 \mathrm{~g} / \mathrm{cm} 3)$ and pore volume.

\section{Absorption kinetics}

To further study the human-like collagen adsorption mechanism of AKF, the Kapok fibers' cumulative adsorption data treated under different alkali concentrations were fitted using the mathematical model of adsorption kinetics. The adsorption kinetic process of solid to liquid phase is generally described using the Quasi-first-order and Quasi-second-order kinetic model (ZengxiaoCai et al.) (Tanzifi et al., 2018), and Weber-Morris internal diffusion model (Hubbe et al., 2019) (Haque et al., 2020) (Bortoluz et al., 2020).

1) Quasi-first-order kinetic model

The Quasi-first-order kinetic model is a first-order rate equation based on solid adsorption, which is applied to liquid phase adsorption. It is one of the most common models which can be expressed using the following equation:

$$
\log \left(q_{e}-q_{t}\right)=\log q_{e}-\frac{k_{f}}{2.303} t
$$

Where $q_{e}(\mathrm{~g} / \mathrm{g})$ is the equilibrium adsorption amount, $q_{t}(\mathrm{~g} / \mathrm{g})$ is the adsorption amount at time $\mathrm{t}$ and $k_{f}$ is the first-order adsorption rate constant.

2) Quasi-second-order kinetic model

It is based on the assumption that the chemical adsorption mechanism controls the adsorption rate. The chemical adsorption mainly refers to the electron sharing and electron transfer between the adsorbent and adsorbate. The following equation is used to express the Quasi-second order kinetic model:

$$
\frac{t}{q_{t}}=\frac{1}{k_{s} q_{e}^{2}}+\frac{1}{q_{e}} t
$$

Where $k_{s}$ represents the second-order adsorption rate constant.

3) Weber-Morris model

The Weber-Morris internal diffusion model is often used to describe the process of adsorbate 
diffusion in the adsorbent pores. The model first analyzes the control steps in the reaction, followed by calculation of the diffusion rate constant in the adsorbent particles. The following equation is used to calculate the diffusion:

$$
q_{t}=k_{i p} t^{1 / 2}+C
$$

Where $C$ is a constant related to the thickness and boundary layer, $k_{i p}$ is internal diffusion adsorption rate constant.

The Quasi-first-order and Quasi-second-order kinetic models' Parameters are exhibited in Table 3, where $q_{e, \exp }$ and $q_{e, c a l}$ represents the equilibrium adsorption amount estimated from the experiment and model; respectively, while R represent the fitting coefficient. Results show that the Quasi-firstorder kinetic model had a better fitting effect than the Quasi-second-order kinetic model for water, primarily due to closer equilibrium adsorption amount $\left(q_{e, \text { exp }}\right.$ and $\left.q_{e, c a l}\right)$ and higher $R^{2}$ values. However, the fitting effect for human-like collagens indicated that the adsorptions were aligned with both Quasi first- and second-order kinetic models (Fig. 6). Herein, it is more likely that the fiber's adsorption to water is the physisorption mechanism rather than the chemisorption, resulting from Van Der Waals, while the adsorption of human-like collagen is due to the coexistence of physisorption and chemisorption. In the Quasi-first-order kinetic model, the rate constant $\left(k_{f}\right)$ of three liquids decreases with increase in liquid viscosity. Water has the largest rate constant because of its lowest viscosity $(1.07 \mathrm{mPa} \mathrm{s})$. Compare to lower viscosity liquids, the higher viscosity liquids are more difficult to diffuse under small sized pores of the fiber assembly. The $k_{s}$ in the Quasi-second-order kinetic model of human-like collagens show a similar trend as $k_{f}$. Overall, results showed that the higher viscosity liquid has a stronger interaction force on fiber compared to the lower viscosity liquid.

Table 3 Kinetic parameters for Pseudo-first-order and Pseudo-second-order.

\begin{tabular}{|c|c|c|c|c|c|c|c|c|}
\hline \multirow[b]{2}{*}{ Adsorbate } & \multirow[b]{2}{*}{ Adsorbent } & \multirow[b]{2}{*}{$\mathrm{q}_{\mathrm{e}, \exp }\left(\mathrm{g} \mathrm{g}^{-1}\right)$} & \multicolumn{3}{|c|}{ Pseudo-first-order } & \multicolumn{3}{|c|}{ Pseudo-second-order } \\
\hline & & & $\mathrm{q}_{\mathrm{e}, \mathrm{cal}}\left(\mathrm{g} \mathrm{g}^{-1}\right)$ & $\begin{array}{l}k_{f}\left(\mathrm{~s}^{-1}\right) \\
\left(10^{-3}\right)\end{array}$ & $R^{2}$ & $\mathrm{q}_{\mathrm{e}, \mathrm{cal}}\left(\mathrm{g} \mathrm{g}^{-1}\right)$ & $k_{s}\left(10^{-3}\right)$ & $R^{2}$ \\
\hline \multirow{3}{*}{ AKF-2 } & Water & 12.615 & 12.364 & 21.991 & 0.845 & 6.854 & 10.962 & 0.572 \\
\hline & Trauer & 11.965 & 15.528 & 18.400 & 0.995 & 15.318 & 0.817 & 0.941 \\
\hline & MeiQ & 12.105 & 13.564 & 3.039 & 0.998 & 15.413 & 0.174 & 0.957 \\
\hline \multirow{2}{*}{ AKF-4 } & Water & 12.630 & 12.406 & 36.251 & 0.992 & 35.842 & 0.774 & 0.223 \\
\hline & Trauer & 11.440 & 9.153 & 25.056 & 0.983 & 13.349 & 2.523 & 0.992 \\
\hline
\end{tabular}




\begin{tabular}{ccccccccc}
\hline & MeiQ & 12.063 & 12.316 & 7.254 & 0.992 & 13.762 & 0.556 & 0.989 \\
\cline { 2 - 7 } AKF-6 & Water & 12.583 & 12.365 & 51.112 & 0.992 & 21.353 & 2.178 & 0.872 \\
& Trauer & 11.309 & 8.574 & 55.018 & 0.982 & 12.766 & 6.673 & 0.992 \\
& MeiQ & 11.869 & 12.533 & 8.198 & 0.975 & 12.755 & 1.316 & 0.998 \\
\cline { 2 - 7 } AKF-8 & Water & 13.055 & 12.299 & 114.632 & 0.984 & 18.382 & 2.949 & 0.887 \\
& Trauer & 12.014 & 8.592 & 36.341 & 0.984 & 13.430 & 4.603 & 0.992 \\
& MeiQ & 12.018 & 12.552 & 8.544 & 0.982 & 13.518 & 0.957 & 0.992 \\
\hline
\end{tabular}
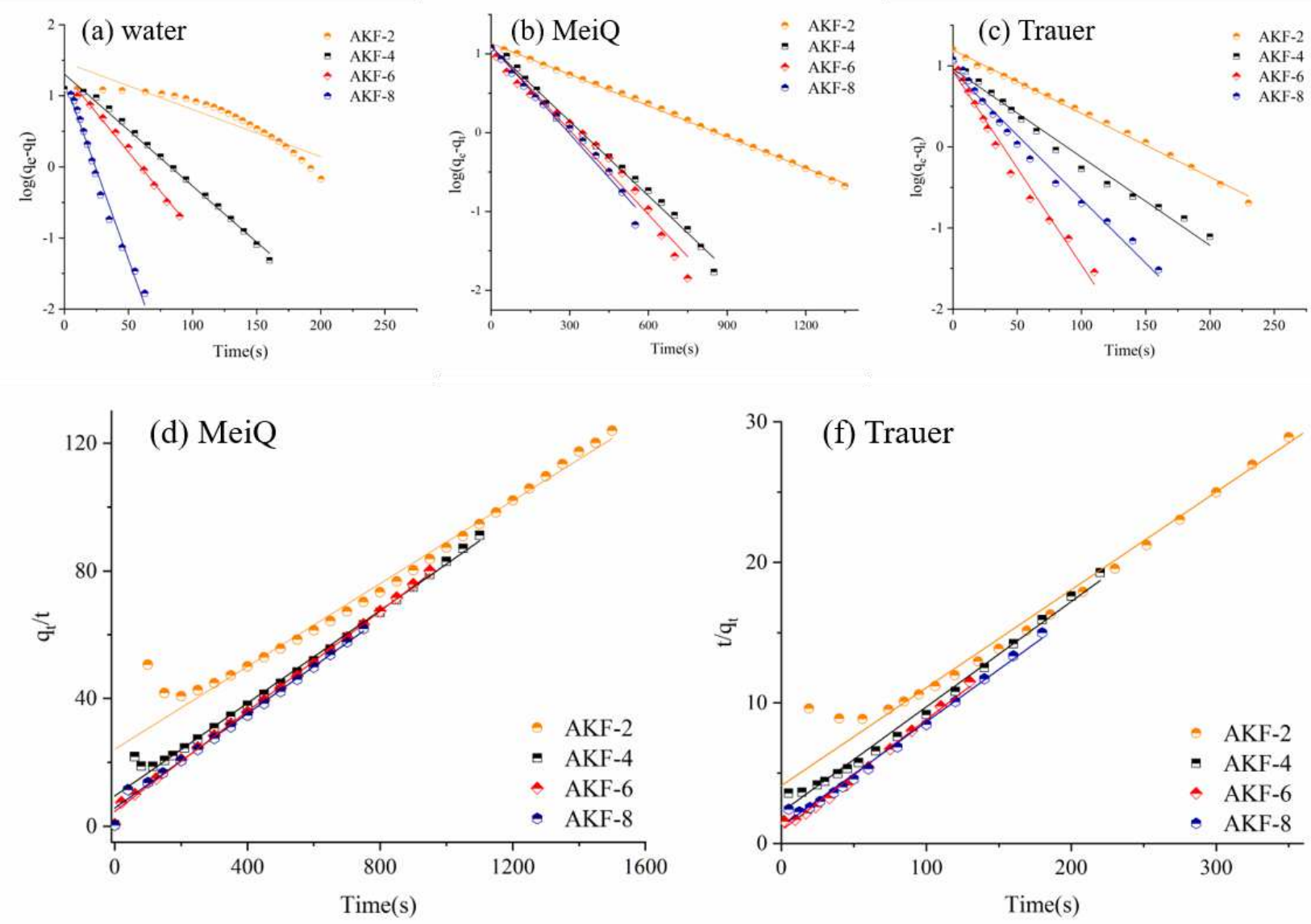

Fig. 6. Quasi-first-order(a-c) and Quasi- second-order kinetic(d-f) model plots of alkali-modified Kapok fiber.

The Weber-Morris model was further used to evaluate the contribution of surface and intraparticle diffusion in the adsorption process. Suppose that the relationship between $q_{t}$ and $t^{1 / 2}$ is not only linear but also passes through the origin. In that case, the Weber-Morris pore diffusion model believes that intraparticle diffusion is assumed to be controlled by a sole rate. As shown in Fig. 7, $q_{t}$ and $t^{1 / 2}$ have a linear relationship, but does not pass through the origin, indicating that the intraparticle diffusion played a positive role in the adsorption steps. However, intraparticle diffusion is not the only step to control the adsorption process because there is other simultaneous adsorption mechanism 
that control adsorption. The curves of $q_{t}$ and $t^{1 / 2}$ are divided into three linear stages (Fig. 7), which implies that there are three consecutive adsorption steps. In the three consecutive adsorption stages of AKF-2, the adsorption capacity of the liquid accounted for $7.42-19.23 \%, 64.38-84.61 \%$ and $5.55-$ $16.39 \%$; respectively, of the total adsorption. Among the three adsorption stages, the second is the main adsorption stage, which resulted in the adsorption of about $57.21-81.08 \%, 43.78-70.57 \%$ and 55.32-75.92\% by AKF-4, AKF-6 and AKF-8, respectively. The $K_{i p}$ value decreases with an increase in human-like collagen's viscosity (Table 4), indicating that lower viscosity can promote diffusion in the fibers. Herein, the adsorption kinetics of AKF to human-like collagen is attributed to both surface and intra-particle diffusion, with the latter playing a more dominant role as the main form of diffusion.

(a)

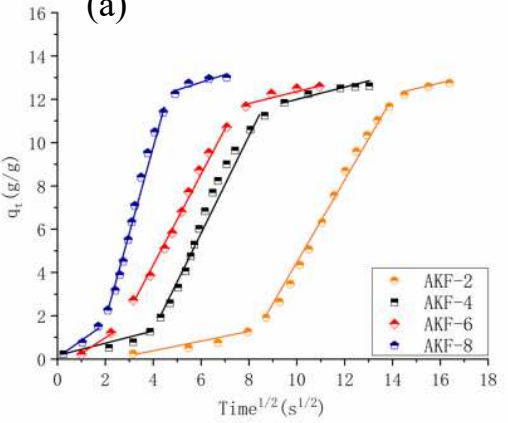

(b)

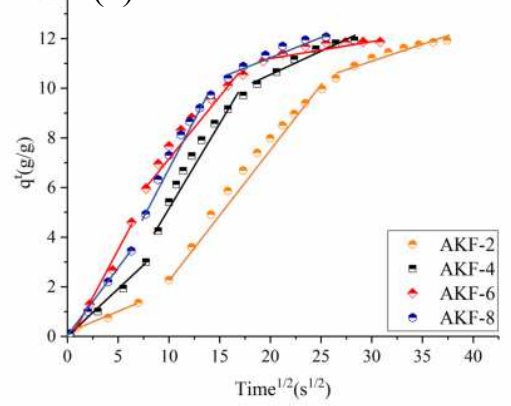

(c)

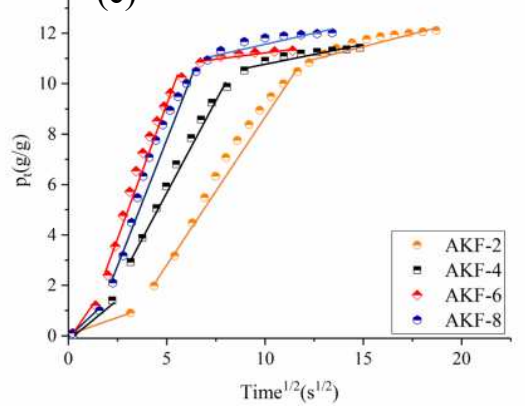

Fig. 7. Weber-Morris model plots of AKF-2, AKF-4, AKF-6 and AKF-8 on Water (a), MeiQ (b) and Trauer (c), respectively.

Table 4 Parameters for Weber-Morris models.

Weber-Morris

\begin{tabular}{|c|c|c|c|c|c|c|c|c|c|c|}
\hline \multirow[t]{2}{*}{ Adsorbate } & \multirow[t]{2}{*}{ Adsorbent } & \multicolumn{3}{|c|}{ First stage } & \multicolumn{3}{|c|}{ Second stage } & \multicolumn{3}{|c|}{ Third stage } \\
\hline & & $\mathrm{C}_{1}$ & $\begin{array}{l}k_{i p 1}(\mathrm{~g} \\
\left.\mathrm{g}^{-1} \mathrm{~s}^{-1}\right)\end{array}$ & $R_{1}^{2}$ & $\mathrm{C}_{2}$ & $\begin{array}{l}k_{i p 2}(\mathrm{~g} \\
\left.\mathrm{g}^{-1} \mathrm{~s}^{-1}\right)\end{array}$ & $R_{2}^{2}$ & $\mathrm{C}_{3}$ & $\begin{array}{l}k_{i p 3}(\mathrm{~g} \\
\left.\mathrm{g}^{-1} \mathrm{~s}^{-1}\right)\end{array}$ & $R_{3}^{2}$ \\
\hline \multirow{3}{*}{ AKF-2 } & Water & 0.468 & 0.199 & 0.850 & 16.079 & 2.030 & 0.994 & 8.113 & 0.284 & 0.933 \\
\hline & Trauer & 0.023 & 0.267 & 0.948 & 3.014 & 1.210 & 0.985 & 8.848 & 0.182 & 0.886 \\
\hline & MeiQ & 0.178 & 0.161 & 0.963 & 2.473 & 0.512 & 0.987 & 7.101 & 0.133 & 0.925 \\
\hline \multirow{3}{*}{$\mathrm{AKF}-4$} & Water & 0.165 & 0.183 & 0.963 & 7.980 & 2.328 & 0.977 & 9.891 & 0.214 & 0.902 \\
\hline & Trauer & 0.133 & 0.698 & 0.986 & 0.989 & 1.361 & 0.978 & 9.973 & 0.099 & 0.942 \\
\hline & MeiQ & 0.072 & 0.382 & 0.988 & 0.247 & 0.584 & 0.952 & 7.391 & 0.165 & 0.923 \\
\hline \multirow{3}{*}{ AKF-6 } & Water & 1.039 & 1.135 & 0.924 & 4.775 & 2.237 & 0.990 & 9.512 & 0.290 & 0.828 \\
\hline & Trauer & 0.143 & 0.965 & 0.995 & 1.103 & 2.092 & 0.970 & 10.308 & 0.093 & 0.820 \\
\hline & MeiQ & 0.219 & 0.720 & 0.972 & 2.846 & 0.464 & 0.962 & 10.034 & 0.064 & 0.777 \\
\hline AKF-8 & Water & 0.728 & 1.384 & 0.959 & 5.815 & 3.886 & 0.968 & 11.835 & 0.168 & 0.845 \\
\hline
\end{tabular}




\begin{tabular}{cccccccccc} 
Trauer & 0.079 & 0.668 & 0.978 & 1.294 & 1.880 & 0.947 & 11.024 & 0.076 & 0.920 \\
MeiQ & 0.038 & 0.553 & 0.9983 & 0.4136 & 0.660 & 0.957 & 8.444 & 0.146 & 0.931 \\
\hline
\end{tabular}

\section{Adsorption mechanism}

As shown in Fig. 9, the adsorption could be broadly divided into three stages which includes surface-, inter-fiber-, and hollow cavity-diffusion. In the first step (i.e., surface diffusion) alkali modification can stimulate the removal of surface wax and expose the hydrophilic hydroxyl groups, which is advantageous in fiber-matrix adhesion and wettability. Compared to raw Kapok fiber, the human-like collagen diffuses on the AKF-2's surface and slowly forms larger liquid droplets (Fig. $8(\mathrm{a})(\mathrm{b}))$. In the second step (i.e., inter-fiber diffusion) a wicking phenomenon occurred under the capillary action of the inter fiber gap to liquid, resulting in the diffusion of adsorbed molecules diffuse to the depths. In the third step (i.e., fiber hollow cavity diffusion), Fig. 8(c)(d) shows that the liquid molecules enter the fiber's hollow cavity because of the presence of numerous multi-level buckling micropores on cell wall and the open ends of the fiber wall, through which the liquid enter the fiber's hollow cavity. These micropores connect the liquid between the hollow cavity and fiber's surface, forming a microporous channel for liquid flow. It is important to note that the second and third step of the adsorption process is intra-particle diffusion caused by the capillary action of effective pore volume and hollow cavity on the liquid. The Kapok fiber's absorption shows a dual-scale liquid adsorption behavior that occurs through both inter-fiber pores and fiber's hollow cavity. The dual adsorption behavior is the primary reason for better adsorption capacity of the Kapok fiber. The force of adsorption is mainly manifested as an orientation force because of the polar macromolecule characteristics of Kapok fiber, and the presence of great dipole moment in the human-like collagen. When two polar molecules approach each other, the molecules will rotate and arrange in a specific direction due to the repulsion of the same polarity, followed by electrostatic attraction. Therefore, the orientation force plays an important role in generating the electrostatic attraction between the permanent dipole of polar molecules. 

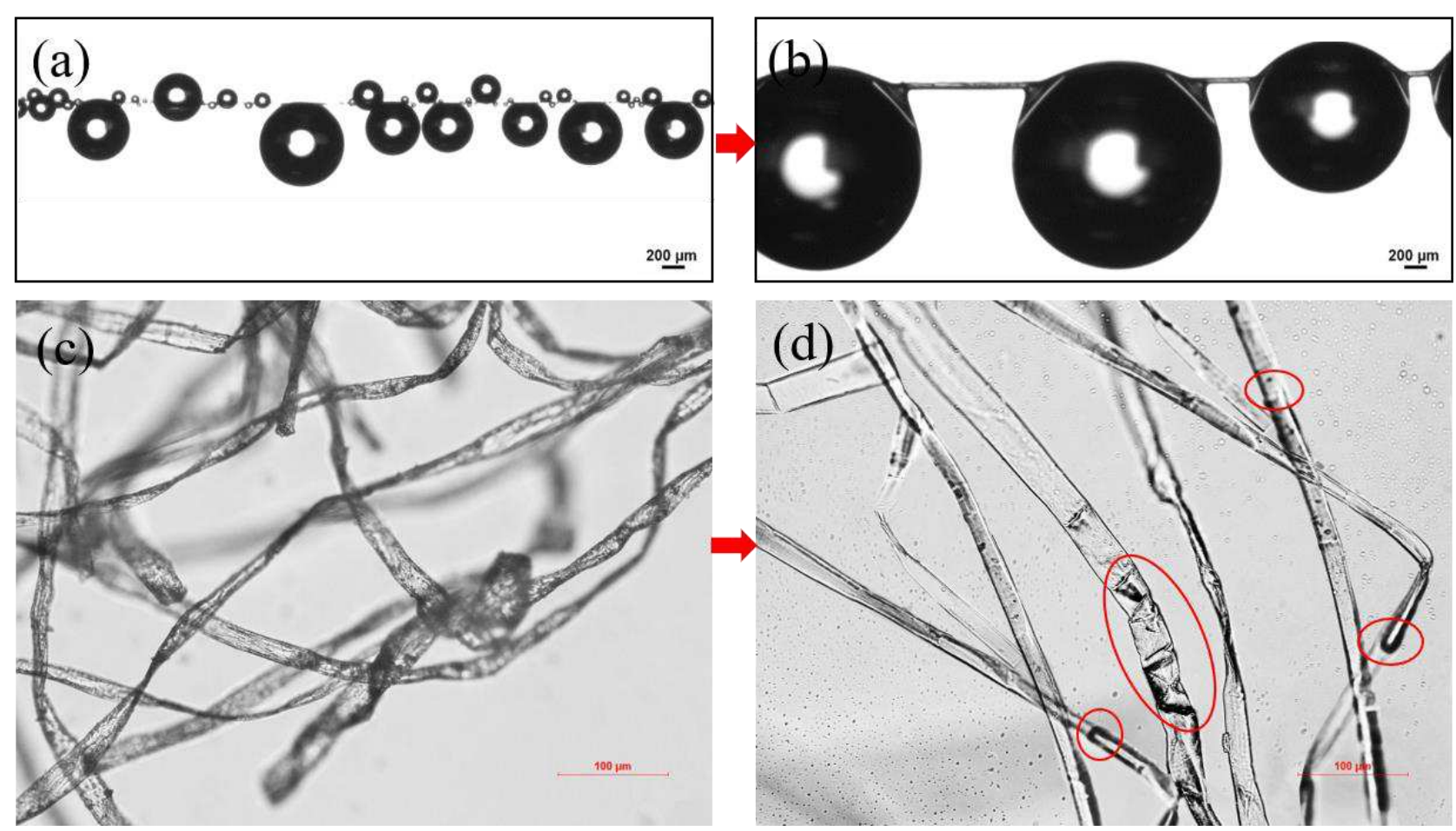

Fig. 8. Adsorption morphology of human-like collagen on the fiber surface, raw Kapok(a) and AKF-2(b).

Micrograph of AKF-2 in nature state (a), water (b) penetrating fiber' hollow cavity.

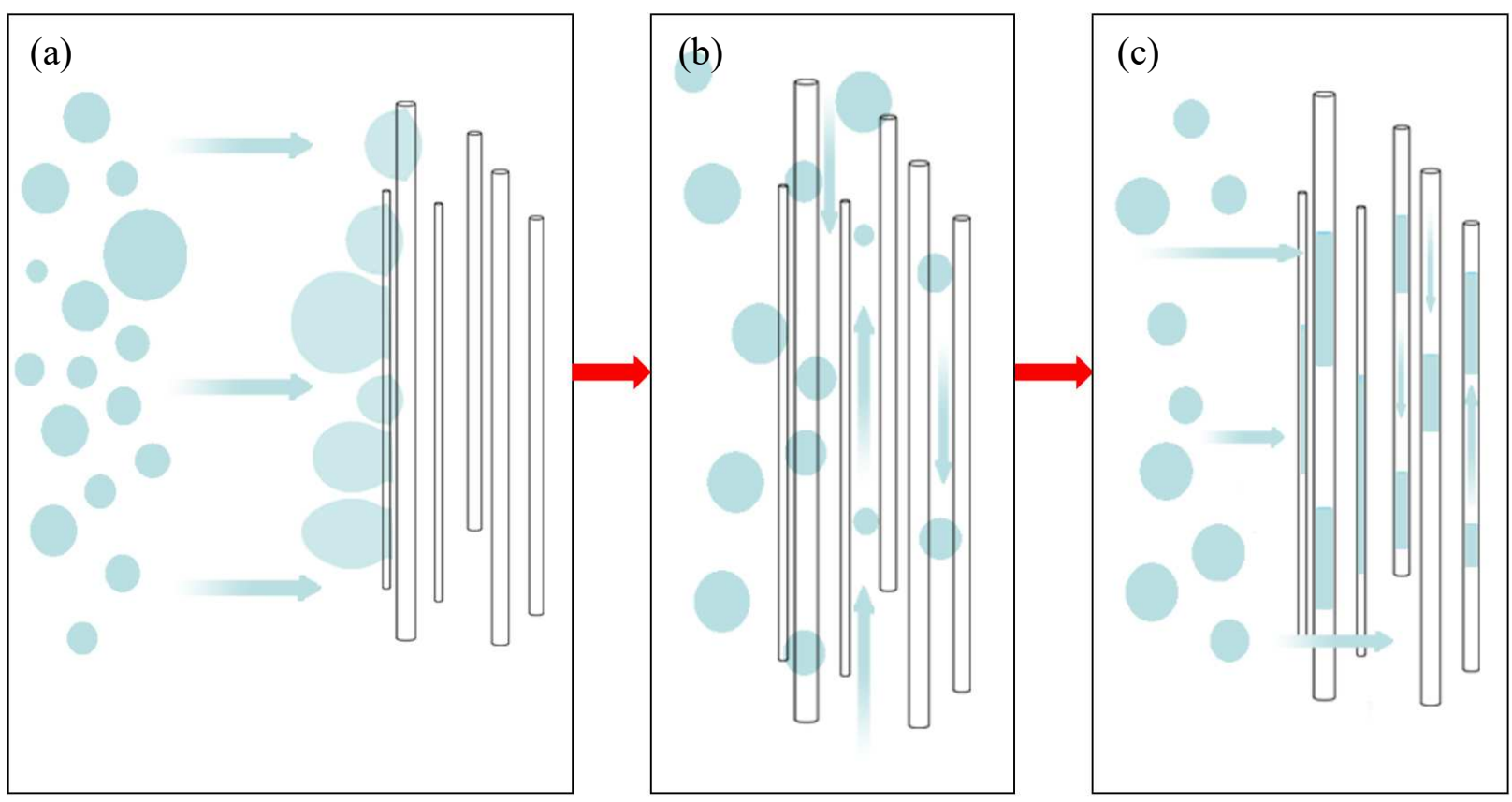

Fig. 9. The three processes of the adsorption of liquid, (a)surface diffusion, (b)inter-fiber diffusion and (c)fiber' hollow cavity diffusion.

The FTIR spectra of AKF-2 and human-like collagen were investigated before and after adsorption to further explore the existence of adsorption mechanisms. The collagen is a polypeptide chain composed of $\alpha$-amino acids formed through peptide bonds. The $\alpha$-carboxylic and $\alpha$-amino at 
both ends of the polypeptide chain can receive or release protons (Han et al., 2019; Pawelec et al., 2016). In the process of adsorption, these groups can form ionic and covalent bonds with hydroxyl and carboxyl groups on the fiber. And the collagen contains a large number of carboxyl, amino and hydroxyl groups, cellulose contains hydroxyl and a small amount of carboxyl groups. The carboxyl, amino and hydroxyl in collagen and the non-ionic area's hydroxyl groups on the plant fiber's surface can form numerous intermolecular hydrogen bonds (Lohrasbi et al., 2020). As show in Fig. 10(a), three absorption peaks at $923.57 \mathrm{~cm}^{-1}, 859.80 \mathrm{~cm}^{-1}$ and $993.63 \mathrm{~cm}^{-1}$, corresponding to the C-H outof-plane bending vibration of MeiQ, and $2880.88 \mathrm{~cm}^{-1}$, corresponding to $\mathrm{C}-\mathrm{H}$ stretching vibration, diminish and disappear after adsorption. The absorption peak at $3304.51 \mathrm{~cm}^{-1}$, corresponding to the $\mathrm{O}-\mathrm{H}$ stretching vibration of AKF-2, slightly shifted, intensified and expanded after adsorption. In comparison (Fig. 10(b)), The absorption peak at $3304.51 \mathrm{~cm}^{-1}$, corresponding to the $\mathrm{O}-\mathrm{H}$ stretching vibration of Traure, slightly shifted and intensified after adsorption. Two absorption peaks at 1554.20 $\mathrm{cm}^{-1}$, corresponding to the $\mathrm{C}=\mathrm{C}$ stretching of Traure, and $1039.80 \mathrm{~cm}^{-1}$, corresponding to the C-C stretching of Traure, amplify after adsorption, while the absorption peak at $1657.96 \mathrm{~cm}^{-1}$, corresponding to the $\mathrm{C}=\mathrm{C}$ stretching of $\mathrm{AKF}-2$, diminish after adsorption. Herein, results show that the physisorption process was primarily accompanied by chemisorption.
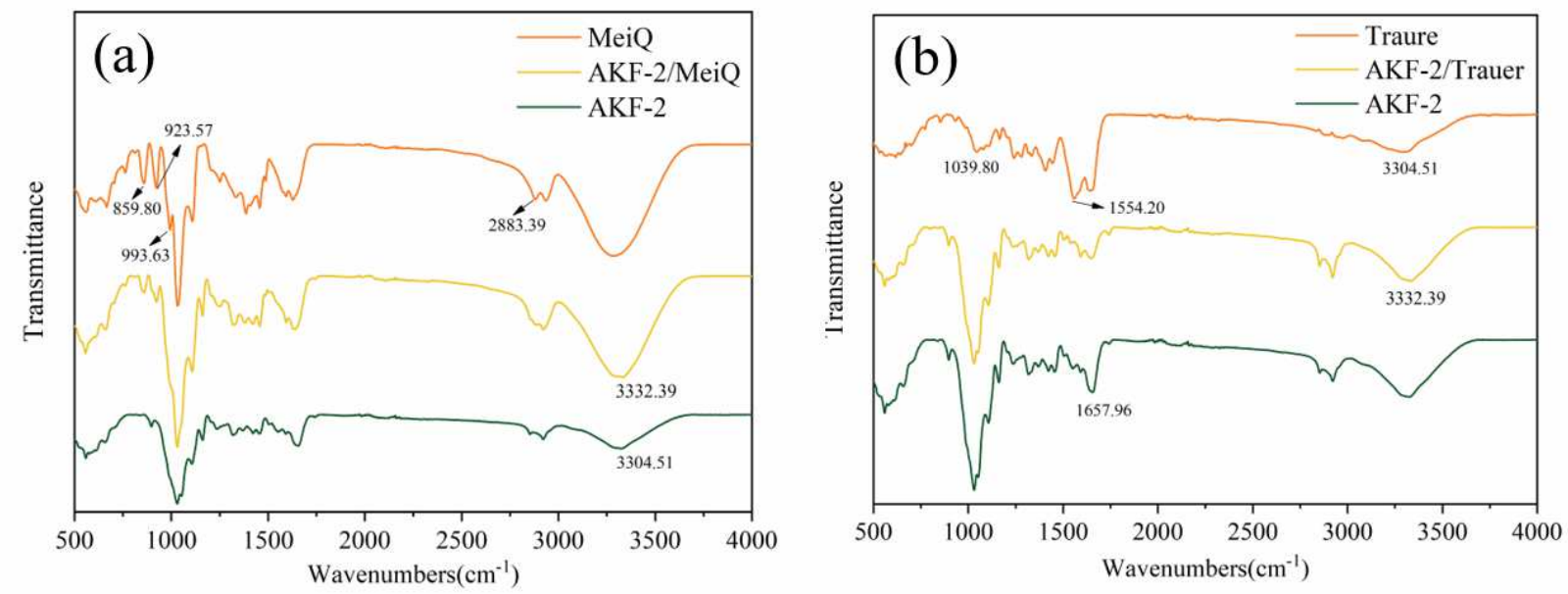

Fig. 10. FTIR spectra of AKF-2 before and after MeiQ adsorption(a) and Trauer adsorption (b)

\section{Conclusion}

We investigated the adsorption kinetic, equilibrium, and mechanistic characteristics of humanlike collagens using different alkali-modified Kapok fibers. Based on our findings, we provide five 
major conclusions that would likely improve our understanding of kinetic, equilibrium and mechanistic features of human-like collagens. (1) The characterization of the AKF showed that the fiber's surface morphology was strongly dependent on alkali concentration, where $2 \%$ of modified $\mathrm{NaOH}$ concentration did not have a significant effect on the hollow cavity structure. The crystallinity increased from $35.71 \%$ to $48.22 \%$ following the increase in alkali concentration from $2 \%$ to $6 \%$. Further increases in alkali concentration from $6 \%$ to $8 \%$ resulted in dropping fiber's crystallinity from $48.22 \%$ to $43.94 \%$. The raw Kapok fiber mainly consists of cellulose (39.95\%), hemicellulose (37.01\%), acid-soluble lignin (11.09\%) and Klason lignin (4.46\%), and the part of hemicellulose and lignin were removed through alkali modification. (2) With further increase in alkali concentration, there is a rapid loss of Kapok fiber's surface energy increase from $7.80 \mathrm{mN} / \mathrm{m}$ to $125.05-140.06$. $\mathrm{mN} / \mathrm{m}$, while the water contact angle decreased from $129.2^{\circ}$ to $48.3-44^{\circ}$. The contact angles of human-like collagens showed a similar trend. (3) The adsorption amount of raw Kapok fiber is around $0.6 \mathrm{~g} / \mathrm{g}$, which accounts for only one twenty-first of adsorption amount of the alkali-treated Kapok. As the $\mathrm{NaOH}$ concentration increase, there was a decrease in adsorption time of human-like collagen time. In contrast, the adsorption time increased with high viscosity. This is primarily due to strong adhesion and large adhesion particle sizes that inhibited diffusion. However, the adsorption amount is not sensitive to alkali concentration because of the same filler density $\left(0.0884 \mathrm{~g} / \mathrm{cm}^{3}\right)$ and pore volume in the Kapok assembly. (4) The absorption data of human-like collagen were described well with both Quasi-first-order and Quasi-second-order kinetic models, indicating the existence of both physisorption and chemisorption. The data also exhibited a better fit to the Weber-Morris model, indicating that the intra-particle diffusion played a positive role in the adsorption steps. (5) The adsorption step could be broadly divided into three stages which include surface, inter-fiber, and hollow cavity-diffusion.

\section{Compliance with ethical standards}

Conflicts of interest: The authors declare that they have no conflict of interest.

\section{References}

Abdullah, M.A., Rahmah, A.U., Man, Z., 2010. Physicochemical and sorption characteristics of Malaysian Ceiba pentandra

(L.) Gaertn. as

a natural

oil

sorbent.

Hazard

Mater 177, 683- 
691.https://doi:10.1016/j.jhazmat.2009.12.085

Andreeva, O.A., Burkova, L.A., Grebenkin, A.N., Grebenkin, A.A., 2002. IR spectroscopic study of prepurified flax. Russ J Appl Chem+ 75, 1513-1516.https://doi:Doi10.1023/A:1022266004482

Andryukov, B.G., Besednova, N.N., Kuznetsova, T.A., Zaporozhets, T.S., Ermakova, S.P., Zvyagintseva, T.N., Chingizova, E.A., Gazha, A.K., Smolina, T.P., 2020. Sulfated Polysaccharides from Marine Algae as a Basis of Modern Biotechnologies for Creating Wound Dressings: Current Achievements and Future Prospects. Biomedicines 8.https://doi:ARTN 30110.3390/biomedicines8090301

Bortoluz, J., Ferrarini, F., Bonetto, L.R., Crespo, J.D., Giovanela, M., 2020. Use of low-cost natural waste from the furniture industry for the removal of methylene blue by adsorption: isotherms, kinetics and thermodynamics. Cellulose 27, 6445-6466.https://doi:10.1007/s10570-020-03254-y

Dong, T., Wang, F.M., Xu, G.B., 2014. Theoretical and experimental study on the oil sorption behavior of kapok assemblies. Ind Crop Prod 61, 325-330.https://doi:10.1016/j.indcrop.2014.07.020

Dong, T., Wang, F.M., Xu, G.B., 2015a. Sorption kinetics and mechanism of various oils into kapok assembly. Mar Pollut Bull 91, 230-237.https://doi:10.1016/j.marpolbul.2014.11.044

Dong, T., Xu, G.B., Wang, F.M., 2015b. Adsorption and adhesiveness of kapok fiber to different oils. J Hazard Mater 296, 101-111.https://doi:10.1016/j.jhazmat.2015.03.040

Dong, T., Xu, G.B., Wang, F.M., 2015c. Oil spill cleanup by structured natural sorbents made from cattail fibers. Ind Crop Prod 76, 25-33.https://doi:10.1016/j.indcrop.2015.06.034

French, A.D., 2014. Idealized powder diffraction patterns for cellulose polymorphs. Cellulose 21, 885896.https://doi:10.1007/s10570-013-0030-4

French, A.D., 2020. Increment in evolution of cellulose crystallinity analysis. Cellulose 27, 54455448.https://doi:10.1007/s10570-020-03172-z

French, A.D., Santiago Cintrón, M., 2013. Cellulose polymorphy, crystallite size, and the Segal Crystallinity Index. Cellulose 20, 583-588.https://doi:10.1007/s10570-012-9833-y

Ge, L.M., Xu, Y.B., Li, X.Y., Yuan, L., Tan, H., Li, D.F., Mu, C.D., 2018. Fabrication of Antibacterial Collagen-Based Composite Wound Dressing. Acs Sustain Chem Eng 6, 9153-9166.https://doi:10.1021/acssuschemeng.8b01482

Guo, X., Liu, Y.N., Bera, H., Zhang, H.T., Chen, Y., Cun, D.M., Fodera, V., Yang, M.S., 2020. alpha-Lactalbumin-Based Nanofiber Dressings Improve Burn Wound Healing and Reduce Scarring. Acs Appl Mater Inter 12, 4570245713.https://doi:10.1021/acsami.0c05175

Han, Y.T., Hu, J.L., Chen, X.Y., 2019. A skin inspired bio-smart composite with water responsive shape memory ability. Mater Chem Front 3, 1128-1138.https://doi:10.1039/c9qm00114j

Hao, Y.P., Zhao, W.W., Zhang, L.Y., Zeng, X., Sun, Z.Y., Zhang, D.M., Shen, P.L., Li, Z.X., Han, Y.T., Li, P.F., Zhou, Q.H., 2020. Bio-multifunctional alginate/chitosan/fucoidan sponges with enhanced angiogenesis and hair follicle regeneration for promoting full-thickness wound healing. Mater Design 193.https://doi:ARTN 10886310.1016/j.matdes.2020.108863

Haque, A.M.A., Remadevi, R., Rojas, O.J., Wang, X.G., Naebe, M., 2020. Kinetics and equilibrium adsorption of methylene blue onto cotton gin trash bioadsorbents. Cellulose 27, 6485-6504.https://doi:10.1007/s10570-020$\underline{03238-y}$

Hubbe, M.A., Azizian, S., Douven, S., 2019. Implications of Apparent Pseudo-Second-Order Adsorption Kinetics onto Cellulosic Materials: A Review. Bioresources 14, 7582-7626

Kaelble, D.H., 1970. Dispersion-Polar Surface Tension Properties of Organic Solids: The Journal of Adhesion: Vol 2, No 2. The Journal of Adhesion.https://doi:10.1080/0021846708544582

Ko, Y.C., Ratner, B.D., Hoffman, A.S., 1981. Characterization of Hydrophilic-Hydrophobic Polymeric Surfaces by Contact Angle Measurements. J Colloid Interf Sci 82, 25-37

Li, J., Ng, D.H.L., Song, P., Song, Y., Kong, C., 2015. Bio-inspired synthesis and characterization of mesoporous 
ZnFe2O4 hollow fibers with enhancement of adsorption capacity for acid dye. J Ind Eng Chem 23, 290298.https://doi:10.1016/j.jiec.2014.08.031

Lohrasbi, S., Mirzaei, E., Karimizade, A., Takallu, S., Rezaei, A., 2020. Collagen/cellulose nanofiber hydrogel scaffold: physical, mechanical and cell biocompatibility properties. Cellulose 27, 927-940.https://doi:10.1007/s10570-019$\underline{02841-y}$

Lozeau, L.D., Youssefian, S., Rahbar, N., Camesano, T.A., Rolle, M.W., 2018. Concentration-Dependent, MembraneSelective Activity of Human LL37 Peptides Modified with Collagen Binding Domain Sequences. Biomacromolecules 19, 4513-4523.https://doi:10.1021/acs.biomac.8b00802

Murray, K.A., Kennedy, J.E., Mcevoy, B., Vrain, O., Ryan, D., Higginbotham, C.L., 2012. The effects of high energy electron beam irradiation on the thermal and structural properties of low density polyethylene. Radiation Physics \& Chemistry 81, 962-966.https://doi:10.1016/j.radphyschem.2011.09.011

Owens, D.K., Wendt, R.C., 1969. Estimation of the surface free energy of polymers. J Appl Polym Sci 13.https://doi: 10.1002/app.1969.070130815

Pallaske, F., Pallaske, A., Herklotz, K., Boese-Landgraf, J., 2018. The significance of collagen dressings in wound management: a review. J Wound Care 27, 692-702.https://doi:10.12968/jowc.2018.27.10.692

Pawelec, K.M., Best, S.M., Cameron, R.E., 2016. Collagen: a network for regenerative medicine. J Mater Chem B 4, 6484-6496.https://doi:10.1039/c6tb00807k

Rabel, W., 1971. Einige Aspekteder Benetzungstheorie und Ihre Anwendung auf die Untersuchung und Veranderung der Oberflacheneigenshaften von Polymeren. Farbe und Lack 77, 997-1005

Rengasamy, R.S., Das, D., Karan, C.P., 2011. Study of oil sorption behavior of filled and structured fiber assemblies made from polypropylene, kapok and milkweed fibers. J Hazard Mater 186, 526532.https://doi:10.1016/j.jhazmat.2010.11.031

Sun, Z.X., Tang, M., Song, Q., Yu, J.Y., Liang, Y., Hu, J., Wang, J., 2018. Filtration performance of air filter paper containing kapok fibers against oil aerosols. Cellulose 25, 6719-6729.https://doi:10.1007/s10570-018-1989-7

Tanzifi, M., Yaraki, M.T., Kiadehi, A.D., Hosseini, S.H., Olazar, M., Bharti, A.K., Agarwal, S., Gupta, V.K., Kazemi, A., 2018. Adsorption of Amido Black 10B from aqueous solution using polyaniline/SiO2 nanocomposite: Experimental investigation and artificial neural network modeling. $J$ Colloid Interf Sci 510, 246261.https://doi:10.1016/j.jcis.2017.09.055

Wang, J.T., Wang, H.F., 2018. Facile synthesis of flexible mesoporous aerogel with superhydrophobicity for efficient removal of layered and emulsified oil from water. J Colloid Interf Sci 530, 372382.https://doi:10.1016/j.jcis.2018.07.002

Wang, J.T., Zheng, Y., Wang, A.Q., 2012. Effect of kapok fiber treated with various solvents on oil absorbency. Ind Crop Prod 40, 178-184.https://doi:10.1016/j.indcrop.2012.03.002

Wang, J.T., Zheng, Y.A., 2017. Oil/water mixtures and emulsions separation of stearic acid-functionalized sponge fabricated via a facile one-step coating method. Sep Purif Technol 181, 183191.https://doi:10.1016/j.seppur.2017.03.024

Wang, R., Shin, C.H., Park, S., Cui, L.Z., Kim, D., Park, J.S., Ryu, M., 2015. Enhanced Antibacterial Activity of SilverCoated Kapok Fibers Through Dopamine Functionalization. Water Air Soil Poll 226.https://doi:ARTN 224110.1007/s11270-014-2241-1

Xiang, H.F., Wang, D., Liu, H.C., Zhao, N., Xu, J., 2013. Investigation on sound absorption properties of kapok fibers. Chinese J Polym Sci 31, 521-529.https://doi:10.1007/s10118-013-1241-8

Yang, Z.L., Yan, J.J., Wang, F.M., 2018. Pore structure of kapok fiber. Cellulose 25, 32193227.https://doi:10.1007/s10570-018-1767-6

Yao, W.Q., Weng, Y.Y., Catchmark, J.M., 2020. Improved cellulose X-ray diffraction analysis using Fourier series modeling. Cellulose 27, 5563-5579.https://doi:10.1007/s10570-020-03177-8 
Ye, J., Shi, X., Chen, X.Y., Xie, J.J., Wang, C.J., Yao, K., Gao, C.Y., Gou, Z.R., 2014. Chitosan-modified, collagen-based biomimetic nanofibrous membranes as selective cell adhering wound dressings in the treatment of chemically burned corneas. J Mater Chem B 2, 4226-4236.https://doi:10.1039/c3tb21845g

ZengxiaoCai, RechanaRemadevi, Faruque, A.A., MohanSetty, LinpengFan, Ahsanulhaque, A.N.M., MaryamNaebe, Fabrication of a cost-effective lemongrass ( Cymbopogon citratus ) membrane with antibacterial activity for dye removal. Rsc Adv 9

Zhang, H., Wang, J., Xu, G., Xu, Y., Wang, F., Shen, H., 2021. Ultralight, hydrophobic, sustainable, cost-effective and floating kapok/microfibrillated cellulose aerogels as speedy and recyclable oil superabsorbents. J Hazard Mater 406, 124758.https://doi:10.1016/j.jhazmat.2020.124758

Zhang, J.P., Wu, L., Zhang, Y.J., Wang, A.Q., 2015. Mussel and fish scale-inspired underwater superoleophobic kapok membranes for continuous and simultaneous removal of insoluble oils and soluble dyes in water. J Mater Chem A 3 , 18475-18482.https://doi:10.1039/c5ta04839g 


\section{Supplementary Files}

This is a list of supplementary files associated with this preprint. Click to download.

- SupportingInformation.docx 